\title{
Vampires! Do they exist? A case of clinical vampirism
}

\author{
D R S Adicaram, E S Wijayamunige, S C A Arambepola
}

\section{Abstract}

Vampirism related to psychiatric disorders has been described under the term, "clinical vampirism". But it is not incorporated as a diagnostic category the ICD or DSM classification systems. We present a case of a 20-year old single, unemployed male who was referred from a drug rehabilitation center, with poor anger control, impulsive behavior and the urge to drink blood, against a background of multiple substance dependence and a IQ of below average. The patient was diagnosed to have mental and behavioural disorders due to multiple substance use, currently in remission, mild mental retardation and dissocial personality disorder. According to the classic description of clinical vampirism, he was having vampirism, without death being involved. He was treated with both pharmacological and nonpharmacological strategies.

Key words: clinical vampirism, auto-vampirism, dissocial personality disorder, multiple substance dependence.

SL J Psychiatry 2021; 12(2): 38-40

\section{Introduction}

European folklore describes vampires as reanimated corpses that seek nourishment from sucking blood from sleeping people (1). Medical conditions such as congenital erythropoietic porphyria and pellagra were considered to be linked with vampires until the relevant pathophysiology was understood (2). In psychiatry, accounts related to vampires have been described in the form of vampiric delusions in schizophrenia or disturbed behaviours of people due to compulsion of drinking blood, in the absence of psychotic illnesses. Psychiatric literature collectively describes these conditions under the term, "clinical vampirism" which is not incorporated as a diagnostic category in the ICD 10 or DSM-5 classification systems (3). Clinical vampirism was further classified by H. Prins as follows (4):

1. Complete vampirism involving ingestion of blood, necrophilic activity, and necro-sadism.

2. Vampirism in which blood ingestion or dead flesh consumption is not evident, similar to pure necrophilia.

3. Vampirism without death being involved.

4. Auto-vampirism - ingestion of one's own blood. The three subdivisions of this phenomenon are,

a) Self-induced bleeding with ingestion of blood.

b) Voluntary bleeding with re-ingestion of blood. c) Auto-haemofetishism - the sight of blood in a syringe drawn up during the intravenous drug addictive practice evokes pleasure, mostly the sexual pleasure.

\section{Case Report}

A 20-year old single, unemployed male was referred from a drug rehabilitation center to the psychiatry clinic. He presented with poor anger control, impulsive behavior and the urge to drink blood, against a background of multiple substance dependence. He had been adopted in his early childhood and there was no childhood features to suggest developmental delays, hyperactivity, impulsivity, or conduct disorder. Although he had failed all the subjects in the GCE $\mathrm{O} / \mathrm{L}$ examination, he was literate and was able to handle money. At the age of 16years he had started consuming alcohol, cannabis, pregabalin, diazepam and tramadol. One year later, he started using heroin and eventually became dependent on the above substances. He started to develop affiliations with many "gangs" and had got involved in many fights. He started to lick the blood on his arms after a fight, at the age of 16 years. He reported that he had done this about 40 times. He claims that he has not attacked people in search of blood, but whenever the opponent was bleeding he had tasted blood of the opponent. He had frequent encounters with law enforcing authorities due to various illegal activities such as stealing, pedaling heroin and he did not express remorse regarding this. 
Two years ago he had started intravenous use of heroin and habitually drank a syringe of blood before injecting heroin. If he wasn't satisfied with his own blood, he would ask his friends to draw blood for him. Eventually he developed the urge to drink blood whenever he heard about blood or saw blood on television.

Although he experienced a sense of satisfaction after ingestion of blood, this act was not associated with obsessions, delusions, hallucinations, sexual gratification or paraphilic behaviour. He did not have any other psychiatric illnesses.

During his stay in the rehabilitation centre he did not engage in ingestion of blood ingestion until two weeks prior to the presentation, when he had seen the wound of an inmate. He had licked blood in that wound. He had also cut his own forearm superficially with a blade, and drank his blood, following which he was referred to the psychiatric clinic. His medical and surgical histories were uncomplicated.

On examination, he had multiple self-inflicted cut injuries over the left forearm and thickened veins over the left cubital fossa. His mood was euthymic, cognitive functions were intact and he had partial insight regarding this. He was keen to take treatment because his partner had rejected him after witnessing his odd behaviour.

Basic investigations, non-contrast CT brain, electroencephalogram (EEG) report, and venereology assessment did not reveal any abnormality. His IQ, as assessed by TONI-3 was below average. During his hospital stay, the patient was treated with risperidone 2 $\mathrm{mg}$ nocte, fluoxetine $20 \mathrm{mg}$ mane, topiramate $50 \mathrm{mg}$ nocte and promethazine $50 \mathrm{mg}$ nocte. He was also taught relaxation techniques, and anger and impulse control strategies using mindfulness, motivational enhancement therapy and cognitive behaviour therapy for heroin dependence. He was referred to a forensic psychiatrist and his risk to others was discerned to be low, and forensic psychiatric interventions were not deemed needed. The patient was included into the high-risk register and was followed up in the clinic.

\section{Discussion}

The patient was diagnosed to have mental and behavioural disorders due to multiple substance use, currently in remission, mild mental retardation and dissocial personality disorder.

According to the classic description of clinical vampirism, he was having vampirism without death being involved. It was not secondary to a psychotic illness and his behaviour was not a result of an obsession, since the idea and the execution of blood ingestion was not distressing.

Literature reports that mental retardation is associated with vampirism, and when vampirism is embedded in an antisocial personality disorder, subjects may present with childhood impulse control difficulties, early tendency to violate rules and lack of empathy towards others $(4,5)$. The existing literature does not provide substantial evidence for definitive management of this condition. Our management for this patient focused more on helping him to control his substance misuse and associated issues; with this management his blood drinking behaviour, anger and impulse control improved. At the time of writing the patient had stopped consumption of psychoactive substances.

Being a rarely reported clinical entity, clinical vampirism may go unnoticed during assessment, as patients may not willingly disclose their urge to drink blood. A high degree of suspicion is needed during assessment of patients with substance misuse, and self-inflicted injuries. Associated dissocial personality traits may complicate the risk assessment and subsequent management. It is important to increase awareness of this condition, which though very rare, may have grave forensic implications.

\section{Declaration of interest}

None declared.

\section{Acknowledgments}

We would like to acknowledge the support extended by the Officer in charge, of the Methsevana Awareness and Rehabilitation Center, Mampitiya Estate, Handessa, Kandy.

\section{Author contributions}

DRSA wrote the report, ESW did the literature review, and DRSA and SCA edited the case report. All authors have seen and approved the final version of the report.

D R S Adicaram, E S Wijayamunige, S C A Arambepola, National Hospital Kandy, Sri Lanka

Corresponding author: D R S Adicaram

Email: dinu284@yahoo.com

D http://orcid.org/0000-0001-9983-8791 


\section{References}

1. Hemphill RE, Zabow T. Clinical vampirism. S Afr Med J 1983; 63: 278-81.

2. Hampl JS, Hampl WS. Pellagra and the origin of a myth: Evidence from European literature and folklore. J R Soc Med 1997; 90:636-9. Available from: https:// www.ncbi.nlm.nih.gov/pmc/articles/PMC1296679/

3. Kelly BD, Abood Z, Shanley D. Vampirism and schizophrenia. Ir J Psychol Med 1999; 16(3): 114-5.
Available from: https://www.cambridge.org/core/journals/ irish-journal-of-psychological-medicine/article/abs/ vampirism-and-schizophrenia/B F 60022419 EF6BF0217088A086E5A765

4. Prins H. Vampirism - A clinical condition. Br J Psychiatry 1985; 146: 666-8. Available from:/record/1986-14650-001.

5. K Gubb, J Segal, A Khota1, A Dicks. Clinical Vampirism: a review and illustrative case report. S Afr Psychiatry Rev 2006; 9: 163-8. 